\title{
Response and Recovery of Eelgrass (Zostera marina) to Chronic and Episodic Light Disturbance
}

\author{
Melisa C. Wong ${ }^{1}$ (D) Benedikte M. Vercaemer ${ }^{1} \cdot$ Gwendolyn Griffiths $^{1}$ \\ Received: 11 February 2020 / Revised: 20 May 2020 / Accepted: 3 July 2020 / Published online: 5 August 2020 \\ (C) The Author(s) 2020
}

\begin{abstract}
Reduced light availability is a leading cause of seagrass declines worldwide. Light deficiency can be chronic or episodic, where pulsed light stress is punctuated by periods of optimal light. Seagrass resilience to light stress is likely modulated by the durations of light stress and the level of light reduction, yet remains poorly understood. We used a laboratory experiment to examine the response and recovery of Zostera marina to 16 weeks of three types of light disturbance: (i) continuous (C; constant shade), (ii) episodic low (EL; cycles of 4 days shade:3 days no shade), and (iii) episodic high (EH; cycles of 12 days shade:2 days no shade), each implemented at three shade levels $(40,60$, and $80 \%$ shade). Declines in shoot density and biomass began after 8 weeks and were highest in $\mathrm{C}$ and $\mathrm{EH}$ disturbance in 60 and $80 \%$ shade. Declines were minimal in $40 \%$ shade across all light disturbances and in EL across all shade levels. Sheath length responded mainly to shade level, initially increasing in 60 and $80 \%$ shade before decreasing. Rhizome carbohydrates initially declined in all light disturbances with $80 \%$ shade but did so earlier in $\mathrm{C}$ and $\mathrm{EH}$ disturbance, and then increased once shoot density decreased. When ambient light was restored, physiological measures recovered, but shoot density, biomass, and morphology did not. Our study showed that shade level strongly modulated Z. marina responses to light disturbance. Not only will chronic high light reduction have negative impacts but pulsed light disturbance can as well, especially when light-stress periods are long and light reduction high.
\end{abstract}

Keywords Chlorophyll $\cdot$ GAMM $\cdot$ Lateral shoots $\cdot$ Light attenuation $\cdot$ Seagrass $\cdot$ Water soluble carbohydrate

\section{Introduction}

Light availability is an important environmental factor that influences the distribution and performance of seagrasses, in part because of their high light requirement relative to other aquatic primary producers (Duarte 1991; Lee et al. 2007). Reduced light availability has played an important role in the decline of global seagrass coverage over the last century (Short and Wyllie-Echeverria 1996; Orth et al. 2006; Waycott et al. 2009), with both chronic and episodic light disturbance

Communicated by Masahiro Nakaoka

Electronic supplementary material The online version of this article (https://doi.org/10.1007/s12237-020-00803-3) contains supplementary material, which is available to authorized users.

Melisa C. Wong

Melisa.Wong@dfo-mpo.gc.ca

1 Bedford Institute of Oceanography, Fisheries and Oceans Canada, Dartmouth, Nova Scotia, Canada being relevant. Chronic light reduction occurs when suboptimal light conditions for seagrasses persist over long periods of time (months or longer), with no opportunity for recovery (Yaakub et al. 2014). Episodic light reduction is characterized by repeated cycles of pulsed light reduction events intermittent with periods of optimal light conditions (Ralph et al. 2007; Biber et al. 2009). Although seagrasses can acclimate to low light conditions by changing their morphology, physiology, biomass, and use of nutrient reserves (Touchette and Burkholder 2000; Lee et al. 2007), plant responses to light stress have mostly been evaluated under chronic light disturbance, despite episodic light reduction being common in the nearshore. Understanding seagrass resilience (i.e., their resistance and recovery; Unsworth et al. 2015) to different patterns in light delivery would allow better management of nearshore human activities to improve underwater light availability and outcomes for seagrasses.

Chronic light reduction in the water column typically results from long-term nutrient loading that promotes growth of algae (Valiela et al. 1997; Hauxwell et al. 2003), overhead structures such as docks or aquaculture cages that shade the 
sea bottom (Burdick and Short 1999; Skinner et al. 2013; Eriander et al. 2017), or persistent elevated water turbidity from eutrophication, runoff, or re-suspended bottom sediments (Giesen et al. 1990; Moore et al. 1997). In contrast, episodic light disturbance results mainly from pulsed water turbidity events related to periodic storms, runoff, wind events, or anthropogenic activities (e.g., dredging). Seagrasses employ several strategies to maintain carbon balance during low light conditions caused by both chronic and episodic light disturbance. They can increase chlorophyll concentration and decrease chlorophyll $a$ to $b$ ratio and maximum electron transport rate to maintain photosynthesis (Ralph et al. 2007; Ochieng et al. 2010; McMahon et al. 2013). They can also maintain carbon balance by reducing growth, leaf length, number of leaves, and shoot density (Ralph et al. 2007; Lee et al. 2007; McMahon et al. 2013) and by mobilizing stored non-structural carbohydrates (Alcoverro et al. 1999).

Although seagrasses will adjust their growth, morphology, and physiology in response to light stress, their ability to persist in low light conditions also depends on the nature of the light reduction events. Studies have shown that extreme chronic shading ( $\leq 10 \%$ of surface irradiance) over prolonged periods of time ( $\geq 3$ months) has severe consequences for various seagrass species (Bulthuis 1983; Fitzpatrick and Kirkman 1995; Lavery et al. 2009; Kim et al. 2015). In these conditions, physiological and morphological changes are not adequate to maintain carbon balance and carbohydrate reserves are exhausted, resulting in plant mortality. With less extreme shading (10-50\% surface irradiance), seagrasses may persist through chronic light reduction, although morphological and physiological changes will be apparent (Bulthuis 1983; Collier et al. 2009; Wong et al. 2020).

Previous studies of episodic light disturbance have shown that seagrasses are negatively impacted when the duration of light stress is longer than periods of optimal light (Biber et al. 2009; Statton et al. 2017). Tropical Indo-Pacific seagrasses (Cymodocea serrulata and Halodule uninervis) responded similarly to this pattern of episodic light disturbance as to chronic low light, with responses modulated by degree of light reduction (Statton et al. 2017). Not surprisingly, the temperate seagrass Zostera marina had stronger negative responses to persistent complete darkness compared with episodic light disturbance, regardless of the pattern in pulsed light delivery (Biber et al. 2009). To our knowledge, the relative importance of chronic versus episodic light disturbance in more moderate light stress scenarios (i.e., not in complete darkness), and how responses are modulated by degree of light reduction, have not been evaluated in $Z$. marina. The response and recovery of this temperate species may differ from tropical seagrasses because it is larger, slower growing, and has higher nutrient stores to support carbon balance (Duarte 1991). The pattern in light delivery (i.e., continuous or pulsed) may not be important when light reduction is low, as plants may easily compensate by adjusting their biomass, morphology, and physiology or without any changes if light remains above minimal requirements. When light reduction is high, episodic light reduction may still have minimal impacts if light stress periods are short relative to optimal light periods, allowing plants to regain carbon balance between light stress periods. On the other hand, high light reduction combined with long pulses of light stress may cause persistent negative carbon balance and high mortality, similar to continuous (chronic) light disturbance. A better understanding of Z. marina resilience to varying light delivery patterns and the influence of shade level would provide guidance as to how nearshore human activities could be better managed to ensure the longterm persistence of this temperate seagrass.

In this study, we assess the response and resilience of the temperate seagrass, Zostera marina, to varying scenarios of episodic and chronic light reduction. In particular, we evaluate how the relative importance of both types of light disturbance is influenced by varying degrees of light reduction and durations of light stress. Z. marina is the dominant seagrass species in Atlantic Canada, where in certain areas it is susceptible to chronic light limitation from nutrient loading (i.e., Southern Gulf of St. Lawrence; Hitchcock et al. 2017; Murphy et al. 2019). However, in many areas of Atlantic Canada, nutrient loading is minimal (Murphy et al. 2019), and episodic light reduction from storms or nearby human activities is the more prevalent type of light disturbance for Z. marina. Light attenuation coefficients $\left(K_{\mathrm{d}}\right)$ ranging from 0.3 to $7 \mathrm{~m}^{-1}$ or even $12 \mathrm{~m}^{-1}$ during extreme weather events have been observed in various $Z$. marina beds in the region (Wong, unpublished data; Krumhansl et al. 2020). We used a laboratory experiment where $Z$. marina plants were exposed to chronic light disturbance (continuous shading) or two types of episodic light disturbance (repeated cycles of 4 days shade and 3 days no shade and 12 days shade and 2 days no shade), using three levels of shading (low, moderate, and high). Seagrass density, biomass, morphology (sheath and leaf length), and physiology (concentrations of total chlorophyll and water soluble rhizome carbohydrates) were measured periodically during the 16week light disturbance period and subsequent 8-week recovery period when ambient light was restored.

\section{Materials and Methods}

\section{Experiment Materials}

Eelgrass (Zostera marina) plants were collected from a large shallow subtidal meadow in Port l'Hebert Bay ( $43^{\circ} 52^{\prime} 04^{\prime \prime} \mathrm{N}$, $\left.64^{\circ} 57^{\prime} 43^{\prime \prime} \mathrm{W}\right)$, Nova Scotia, Canada, 25-28 May 2017. Plants were transferred to the Bedford Institute of Oceanography in coolers and held in tanks with seawater for $24 \mathrm{~h}$ until planted into the experimental tanks. The 
experimental tanks were made of glass and measured $60 \mathrm{~cm}$ long $\times 30 \mathrm{~cm}$ wide $\times 30 \mathrm{~cm}$ high. Each tank had its own source of flow-through seawater delivered at 2-2.5 $\mathrm{L} \mathrm{min}^{-1}$. Sixty vegetative shoots with $3-4 \mathrm{~cm}$ rhizome and roots attached were planted in an even distribution into plastic trays containing $5 \mathrm{~cm}$ sandy sediment, which were then submerged into the tanks. The sediment was $\sim 86 \%$ sand, $12 \%$ gravel, and $2 \%$ $\mathrm{mud} / \mathrm{silt}$, and while less muddy than the collection site, was similar to sediment conditions commonly observed for relatively exposed eelgrass beds in the region (Wong 2018). Light was provided to each tank using LED wide spectrum light strips (Sunblaster), and photosynthetically active radiation (PAR) was $\sim 150 \mu \mathrm{mol} \mathrm{m} \mathrm{m}^{-2}$ at mid-canopy level, which represents median PAR at the field collection site during the experiment (Wong, unpublished data). The photoperiod was maintained at $14 \mathrm{~h}$ light:10 h dark. Plants were allowed to acclimate for 2 weeks after planting before the experiment began. The experiment was conducted from 15 June to 30 November 2017. During the acclimation period, water temperatures were incrementally raised from 8 to $12{ }^{\circ} \mathrm{C}$ and then maintained; this represents mean temperature in similar seagrass beds during the experiment (Krumhansl et al. 2020). Some epiphytic algae growth occurred during the experiment and was periodically cleaned and removed from the tanks.

\section{Experimental Design and Plant Collections}

We simulated three different types of light disturbance relevant for temperate eelgrass beds in the region. These included chronic light disturbance (continuous shade), episodic low disturbance (repeated cycles of 4 days shade: 3 days no shade), and episodic high disturbance (repeated cycles of 12 days shade: 2 days no shade). The chronic disturbance was intended to represent light reduction from long-term nutrient loading prevalent in some areas of Atlantic Canada (Murphy et al. 2019), while episodic disturbance represented pulsed light stress from seasonal storm events or nearshore marine construction. Each type of light disturbance was implemented for three different levels of shading: 40,60 , and $80 \%$ reduction of ambient light measured at mid-canopy (Fig. 1), based on representative field measurements and to provide a gradient of light reduction. Tanks were shaded using single or double layers of greenhouse shade cloth (sold as 30,50, and 70\% shade cloth, ShelterLogic, Watertown, CT, USA) that covered the top and sides of the tanks. Light disturbance was implemented for 16 weeks, after which time all shades were removed for an 8-week recovery period. Six replicates of each combination of light disturbance and shade level were randomly allocated to the experimental tanks. Six control tanks with no light disturbance or shade were also included.

Plant response to the light disturbance treatments was evaluated using measures of shoot density, biomass, morphology (sheath and leaf length), and physiology (concentrations of chlorophyll and water-soluble rhizome carbohydrates). Sampling was conducted at the initiation of the experiment and every 4 weeks thereafter. Sampling periods thus included 0 weeks (no light disturbance), 4, 8, 12, and 16 weeks (light disturbance period), and 20 and 24 weeks (recovery period). At each sampling period, shoot density was visually assessed by counting the number of living shoots per tank, except the last time period when all plants were excavated and counted. One shoot per tank was collected at each time period, and sheath length and length of the third oldest leaf were measured. After measurements, the shoot was separated from the rhizome. Chlorophyll concentration ( $a$ and $b$ ) was extracted from a ground $20 \mathrm{~mm}$ mid-section of the third oldest leaf using a 2:1 solution of $90 \%$ acetone and $100 \%$ dimethylsulfoxide (Shoaf and Lium 1976) for all sampling periods except weeks 12 and 20 when samples were not available. Total chlorophyll concentration was determined from the extracts using spectrophotometry readings at 665,652 , and $750 \mathrm{~nm}$ and equations from Ritchie (2006) and Wong et al. (2020). Rhizome watersoluble carbohydrates were hydrolyzed from a $5-$ to $8-\mathrm{cm}$ ground-dried rhizome section using $80 \%$ ethanol and heated to $80^{\circ} \mathrm{C}$ and then centrifuged at $13,000 \times g$ for $15 \mathrm{~min}$. Soluble sugar content in the supernatant was determined using the phenol sulfuric acid method in a microplate assay read at $490 \mathrm{~nm}$ (Masuko et al. 2005; Wong et al. 2020). At the end of the experiment, all plant material was excavated from the tanks and above- and belowground biomass was determined by drying the material at $60{ }^{\circ} \mathrm{C}$ for $48 \mathrm{~h}$.

\section{Statistical Analyses}

Light disturbance type and shade level were combined into one treatment factor for the analyses, allowing statistical comparison between the light stress treatments and controls. Hereafter, we refer to this factor as light disturbance regime, which had ten levels: no disturbance (control), episodic low disturbance with 40,60 , or $80 \%$ shade, episodic high disturbance with 40,60 , or $80 \%$ shade, and continuous disturbance with 40,60 , or $80 \%$ shade. The effect of light disturbance on Z. marina shoot density, morphology (sheath length), or physiology (concentrations of total chlorophyll, rhizome watersoluble carbohydrates) was examined using generalized additive mixed models (GAMMs), with the fixed factor light disturbance regime (10 levels), the covariate time from initiation of the experiment (5-7 levels), and the random factor tank, which was nested within light disturbance regime. Additive models such as GAMMs allow for flexible specification of the dependence of the response variable on the covariate(s) by using a sum of smoothed functions of one or more covariates (Wood 2017). Additive models are thus appropriate to model non-linear relationships between the response and covariate, which have been observed for seagrass variables over time 


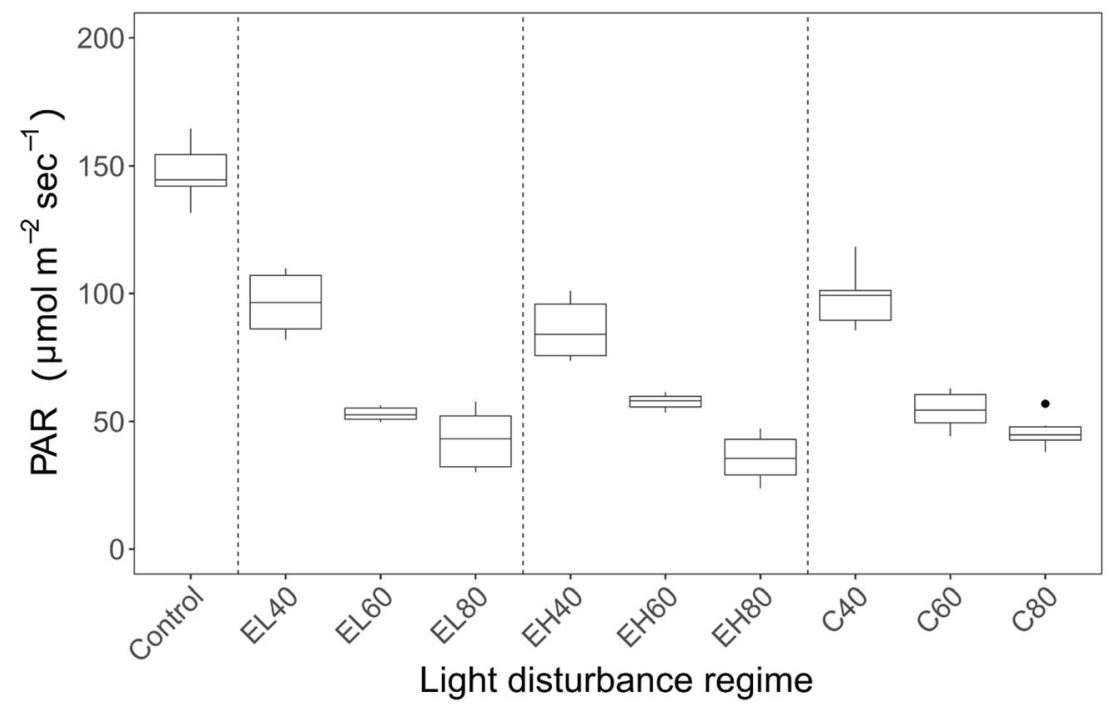

Fig. 1 Photosynthetically active radiation (PAR) measured in the different light disturbance regimes. Control, no light disturbance; EL, episodic low disturbance (cycles of 4 days shade:3 days no shade); $\mathrm{EH}$, episodic high disturbance (cycles of 12 days shade: 2 days no shade); C, continuous disturbance (continuous shade). Numbers associated with

and over various environmental variables (Olsen et al. 2012; Lefcheck et al. 2017). We used the following GAMM model to identify patterns in the different eelgrass response metrics over time for the different light disturbance regimes:

$$
\begin{aligned}
y_{i}= & \mathbf{X}_{i} \boldsymbol{\beta}+\mathbf{Z}_{i} \mathbf{b}+f_{1}\left(\text { time }_{i}\right) \\
& +\epsilon_{i}, \quad \epsilon \sim N\left(0, \sigma^{2} \mathbf{I}\right), \quad b \sim N(0, \mathbf{\Psi})
\end{aligned}
$$

Here, $y_{i}$ represents a single observation $(i=1, \ldots, 60)$ of the eelgrass response metric of interest. The fixed factors are given by the vector $\boldsymbol{\beta}$, each element of which corresponds to a different light regime. The random effects are represented by the vector $\mathbf{b}$ designating the tank effect. The row vectors $\boldsymbol{X}_{i}$ and $\mathbf{Z}_{i}$ assign the observation to the appropriate light level (fixed effect) and tank (random effect), respectively. The response also considers a smooth function of time as given by the term $f_{1}\left(\right.$ time $\left._{i}\right)$. The error vector $\epsilon$ is assumed to be an independent and identically distributed normal random vector with unknown variance $\sigma^{2}$. The random effects coefficients, $\mathbf{b}$, follow a zero-mean, multivariate normal with unknown covariance matrix $\Psi$. A primary goal for inference is estimating the fixed effects $\boldsymbol{\beta}$ and the functional dependence of the response on time, $f_{1}\left(\right.$ time $\left._{i}\right)$. The variance $\sigma^{2}$ and $\Psi$ (or parameters controlling it) are also estimated. Cubic regression splines were used to parameterize the smooth function $f_{1}\left(\right.$ time $\left._{i}\right)$ and models were fit using restricted maximum likelihood (Wood 2017). Shoot density was adjusted to account for shoots removed for morphometric and physiological measurements and was evaluated across all sampling periods except the last, when some lateral shoots undetected during visual counts became apparent when plants were excavated from the tanks. each light disturbance category represent 40,60 , or $80 \%$ reduction of ambient light (control level) at mid-canopy. Each box shows the range of data between the first and third quartiles (interquartile range (IQR)), the horizontal line represents the median, the whiskers indicate $\pm 1.5 * \mathrm{IQR}$, and the points indicate outliers

Sheath length and rhizome carbohydrates were evaluated for the light stress period only, to allow clear observations of differences from the controls that would otherwise have been masked by inclusion of the recovery period. Sheath length was highly correlated with leaf length $(R=0.93)$, and so only sheath length is presented.

The effects of light disturbance regime on shoot density, aboveground biomass, and belowground biomass at the end of the experiment (week 24) were examined using linear regression. For both linear and GAMM regressions, significance of smoothers and light disturbance regimes relative to the control was evaluated using $p$ values from the regression statistics $(p<0.10)$. Differences between light disturbance regimes were evaluated from observations of the data. Residual plots were evaluated to assess the assumptions of homogeneity of variance and normality. Aboveground biomass was square root transformed and belowground biomass was $\log _{10}($ datum +1$)$ transformed to meet assumptions, but in all other cases, assumptions were not violated. Temporal autocorrelation for GAMM models was evaluated using autocorrelation function plots, with no autocorrelation evident for any analysis. All regression analyses were conducted in R Studio (1.2.5033), with GAMM modeling implemented using the package "mgcv."

\section{Results}

\section{Shoot Density}

Shoot density decreased significantly in all light disturbance regimes after 8 weeks relative to the control, which increased 
at 8 weeks before returning to initial density (GAMM regression: $R^{2}=0.708$; smoother terms: $d f=1-4.7, F=4.4-61.2$, $p<0.0001$ to 0.03 ; Fig. 2a, b; Electronic supplement S1). The effects of the different types of light disturbance on shoot density were highly modulated by the degree of shading. When shading was moderate or high (60 or $80 \%$ ), declines in shoot density became increasingly larger as light disturbance intensified (i.e., length of shading period increased), illustrated by the increasingly negative slopes of the smoother functions (Fig. 2b). By the end of the light disturbance period (week 16), shoot density at these shade levels was significantly higher in episodic low disturbance compared with both episodic high and continuous (Fig. 2a). Continuous and episodic high disturbance had similar density at week 16 in $60 \%$ shade but not $80 \%$ shade, where it was lower in continuous disturbance (Fig. 2a). When shading was low (40\%), declines in shoot density across all light disturbance types were of less magnitude than observed at higher shade levels (Fig. 2b), with density being lower in continuous disturbance than in episodic low or high disturbance. Shoot density in episodic high and continuous light disturbance strongly decreased as shade level
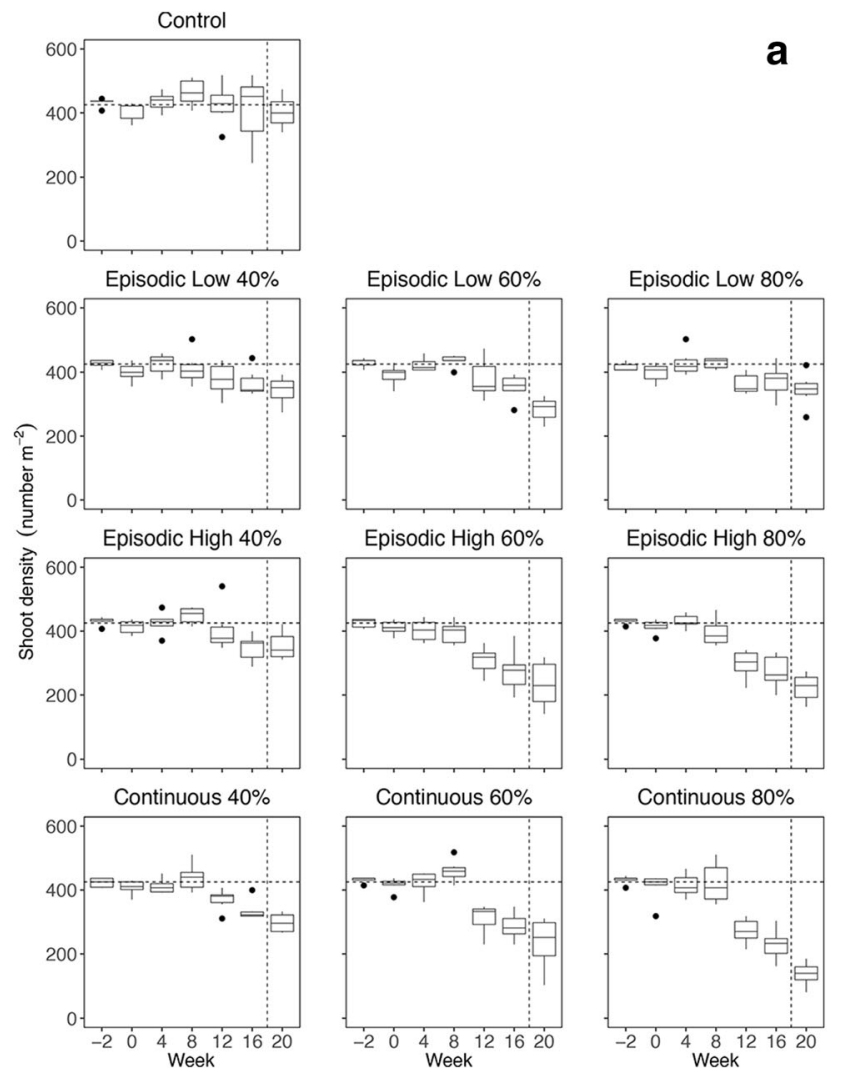

Fig. 2 a Shoot density measured during acclimation, the light disturbance period, and the recovery period. Week -2 indicates when the 2-week acclimation period began, week 0 indicates when the light disturbance began, and the vertical dotted line indicates when shades were removed and recovery began (at 16 weeks). The horizontal dotted line indicates mean shoot density observed in the control. Boxplot as defined in Fig. 1. increased, with shoot density being lower in $80 \%$ shade relative to $60 \%$ only when light stress was continuous. Shoot density did not decrease with increasing shade level in episodic low disturbance.

When light disturbance was removed and plants allowed to recover, no recovery in shoot density was evident for any experimental treatment by week 20 , with density continuing to decrease in the majority of treatments (Fig. $2 a, b)$. Shoot density at week 24 , when plants were excavated from the tanks, also showed no recovery of shoot density to background levels (linear regression: $R^{2}=0.69$, $F_{9,50}=12.7, p<0.0001$; parameter coefficients: $t=-1.6$ to $-7.8, p<0.001$ to 0.1 ; Fig. 3; Electronic supplement $\mathrm{S} 1$ ), despite inclusion of lateral shoots that were not apparent during previous visual counts. Lateral shoot density ranged from 9 to $23 \%$ of total shoot density (Fig. 3) and was significantly lower in episodic high disturbance at all shade levels and in continuous disturbance at 60 and $80 \%$ shade relative to the controls (linear regression, square root transformed: $R^{2}=0.38 ; F_{9,50}=3.46, p=0.002$; parameter coefficients: $t=-3.24$ to $-2.01, p=0.002$ to 0.049 ).
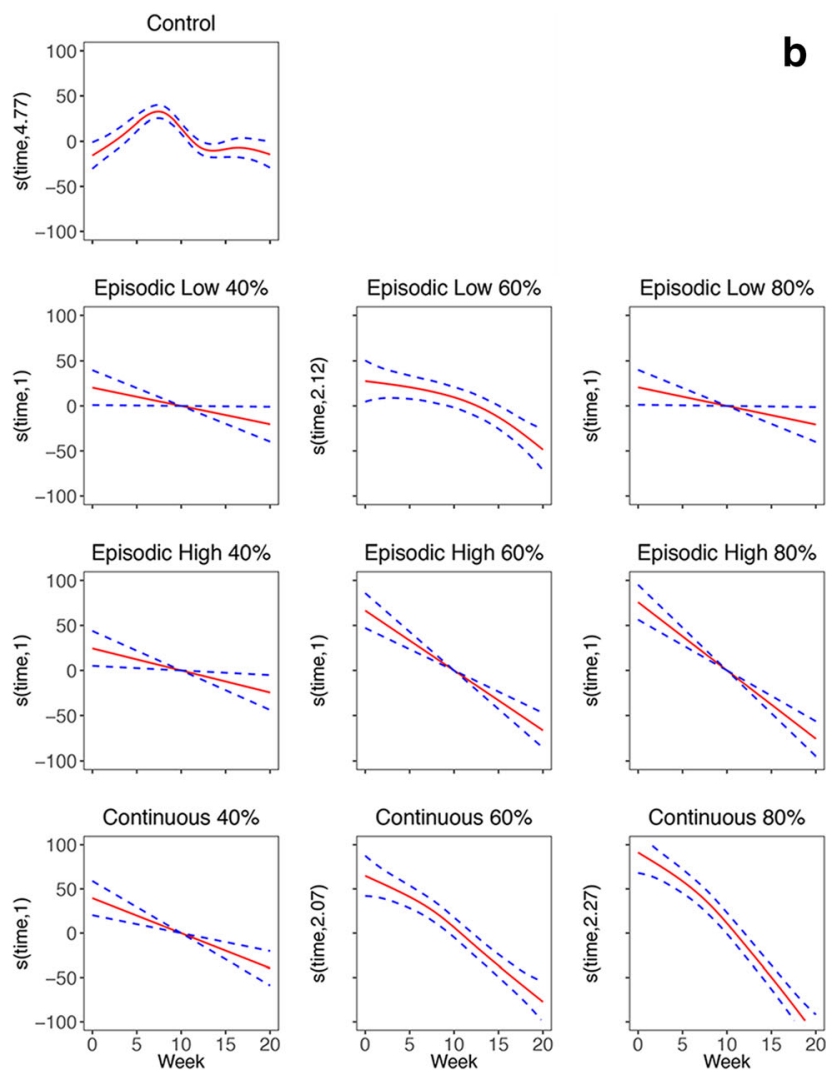

b Smoother functions for shoot density over time as estimated by the GAMM regression for the whole experiment. The red solid line indicates the estimated function, and the blue dotted lines indicate confidence intervals based on 2 standard errors. Numbers in the parentheses on the $y$-axes are the effective degrees of freedom for that treatment level 
Fig. 3 Number of total shoots (adult + lateral) and lateral shoots in the different light disturbance regimes at the end of the experiment (week 24), determined after tanks were excavated. Control, no light disturbance; EL, episodic low disturbance (cycles of 4 days shade: 3 days no shade); $\mathrm{EH}$, episodic high disturbance (cycles of 12 days shade: 2 days no shade); $\mathrm{C}$, continuous disturbance (continuous shade). Values associated with each light disturbance category represent 40 , 60 , or $80 \%$ reduction of ambient light (control level) at the midcanopy. Dotted vertical lines separate each light disturbance type. Boxplot as defined in Fig. 1

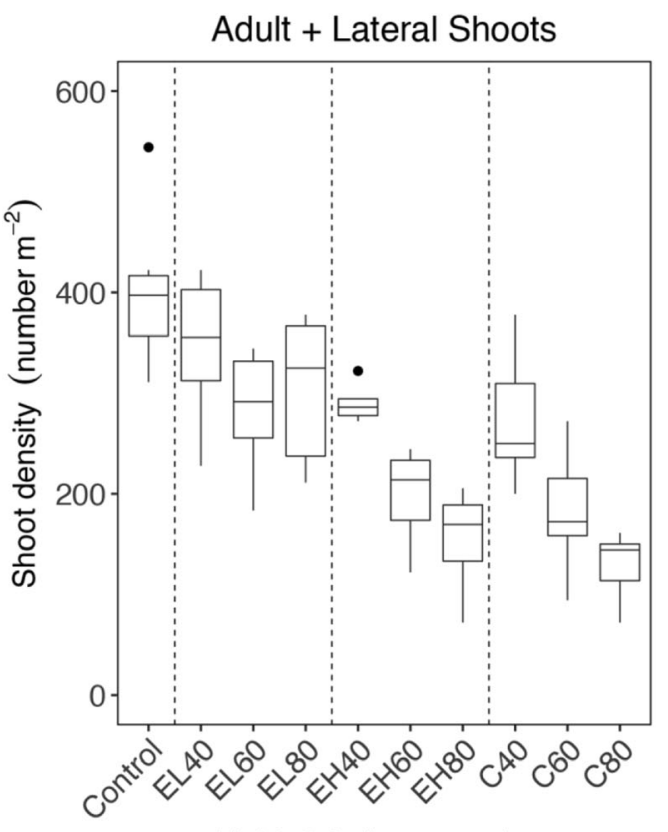

Light disturbance regime

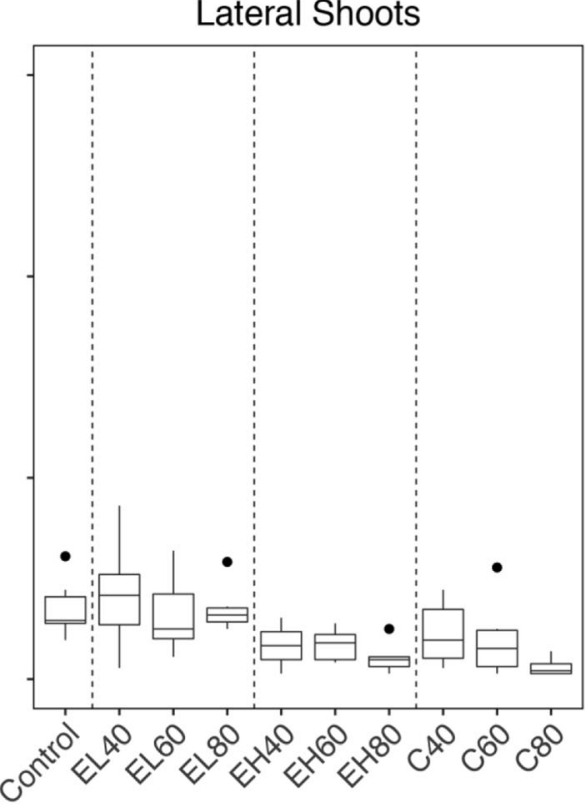

Light disturbance regime
Lateral shoot density was lowest in continuous disturbance at $80 \%$ shade.

\section{Above- and Belowground Biomass}

Aboveground biomass at the end of the experiment was significantly lower than controls in all light disturbance regimes, except for episodic low disturbance with $40 \%$ shade (linear regression, square root transformed: $R^{2}=0.73, F_{9}, 50=14.9$, $p<0.0001$; parameter coefficients: $t=-2.36$ to -8.72 , $p<0.0001$ to 0.022; Fig. 4a; Electronic supplement S1). Aboveground biomass progressively decreased across increasing shade level in both episodic high and continuous disturbance, with lowest biomass in continuous disturbance with $80 \%$ shade. Belowground biomass was significantly lower than controls in episodic high disturbance at 60 and $80 \%$ shade (linear regression, $\log _{10}($ data +1$): R^{2}=0.54, F_{9}$, ${ }_{50}=6.49, p<0.0001$; parameter coefficients: $t=-3.37$ and $-3.68, p=0.001$ and 0.0005 ; Fig. $4 b$ ), continuous disturbance across all shade levels (parameter coefficients: $t=-1.81$ to $6.41, p<0.0001$ to 0.07 ), and in episodic low disturbance at $60 \%$ shade (parameter coefficient: $t=-2.14, p=0.037$ ). As observed for aboveground biomass, belowground biomass was lowest in continuous disturbance with $80 \%$ shade.

\section{Morphology (Sheath Length)}

Smoother functions indicated that sheath length tended to increase over time in all light disturbance regimes relative to the controls and was mainly influenced by shade level (GAMM regression: $R^{2}=0.160$; Fig. 5a, b; Electronic supplement $\mathrm{S} 1$ ). Sheath length in all light disturbance regimes with $40 \%$ shade did not differ significantly from controls (smoother terms: $d f$ $=1, F=1.79$ to $1.95, p=0.162$ to 0.181 ) (Fig. 5b). In all light disturbance regimes with $60 \%$ shade, smoother functions indicated that sheath length increased significantly relative to control plants during light disturbance (smoother terms: $d f=$ 1 to $1.6, F=4.25$ to $7.29, p=0.007$ to 0.06 ; Fig. 5 b), although some declines at week 12 (episodic low) and week 16 (episodic high and continuous) are evident in the data (Fig. 5a). Smoother functions in all episodic light disturbance regimes with $80 \%$ shade indicated that sheath length also increased significantly relative to control plants, although to a lesser extent than observed for $60 \%$ shade (i.e., slope of smoother functions were less; smoother terms: $d f=1, F=2.841$ to 3.16, $p=0.007$ to 0.093 ; Fig. 5b). Again, some declines are apparent at week 16 in the data (Fig. 5a). During the recovery period, sheath length continued to decrease in episodic high and continuous disturbance at $80 \%$ shade and in continuous disturbance at $60 \%$ shade.

\section{Physiological Measures}

The GAMM regression indicated that while total chlorophyll concentration did not tend to differ among light disturbance regimes, different patterns in chlorophyll over time were observed in all light stressed plants relative to the controls (GAMM regression: $R^{2}=0.225$; Fig. 6a, b; Electronic supplement S1). Smoother functions indicated that chlorophyll concentration increased in the control during the light disturbance period (smoother term: $d f=1, F=12.7, p=0.0004$; Fig. 6b) but had either a negative linear or quadratic function across time in all light disturbance regimes. Note that most of these smoother functions were non-significant, with the exception 
Fig. 4 Above- and belowground biomass in the different light disturbance regimes at the end of the experiment (week 24). Control, no light disturbance; EL, episodic low disturbance (cycles of 4 days shade: 3 days no shade); $\mathrm{EH}$, episodic high disturbance (cycles of 12 days shade: 2 days no shade); $\mathrm{C}$, continuous disturbance (continuous shade). Numbers associated with each light disturbance category represent 40,60 , or $80 \%$ reduction of ambient light (control level) at the mid-canopy. Dotted vertical lines separate each light disturbance type. Boxplot as defined in Fig. 1

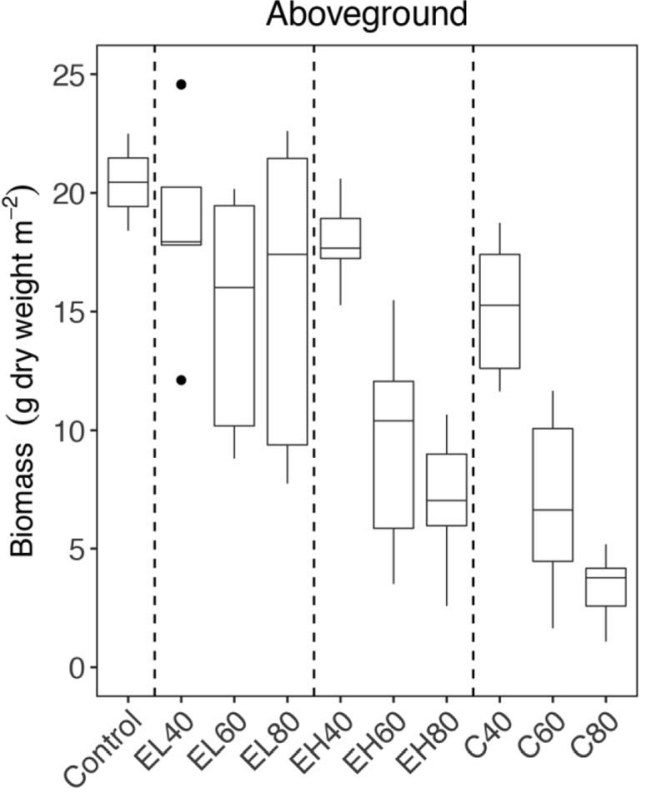

Light disturbance regime
Belowground

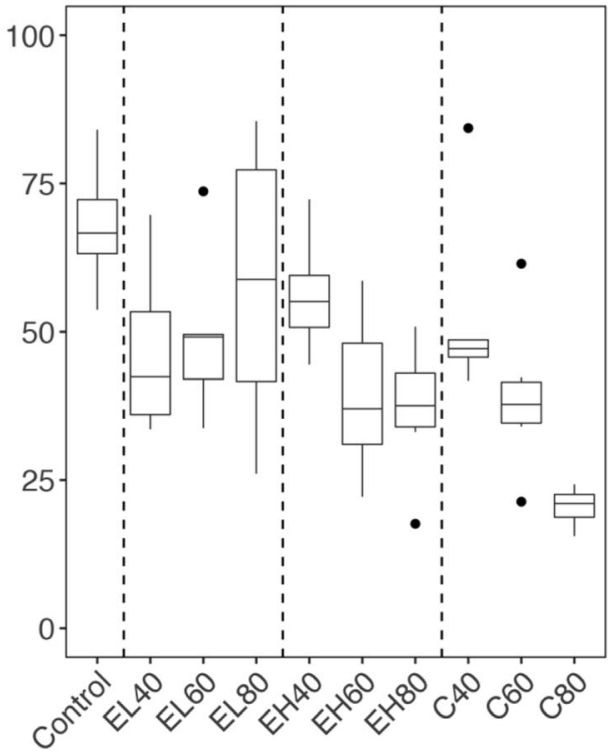

Light disturbance regime
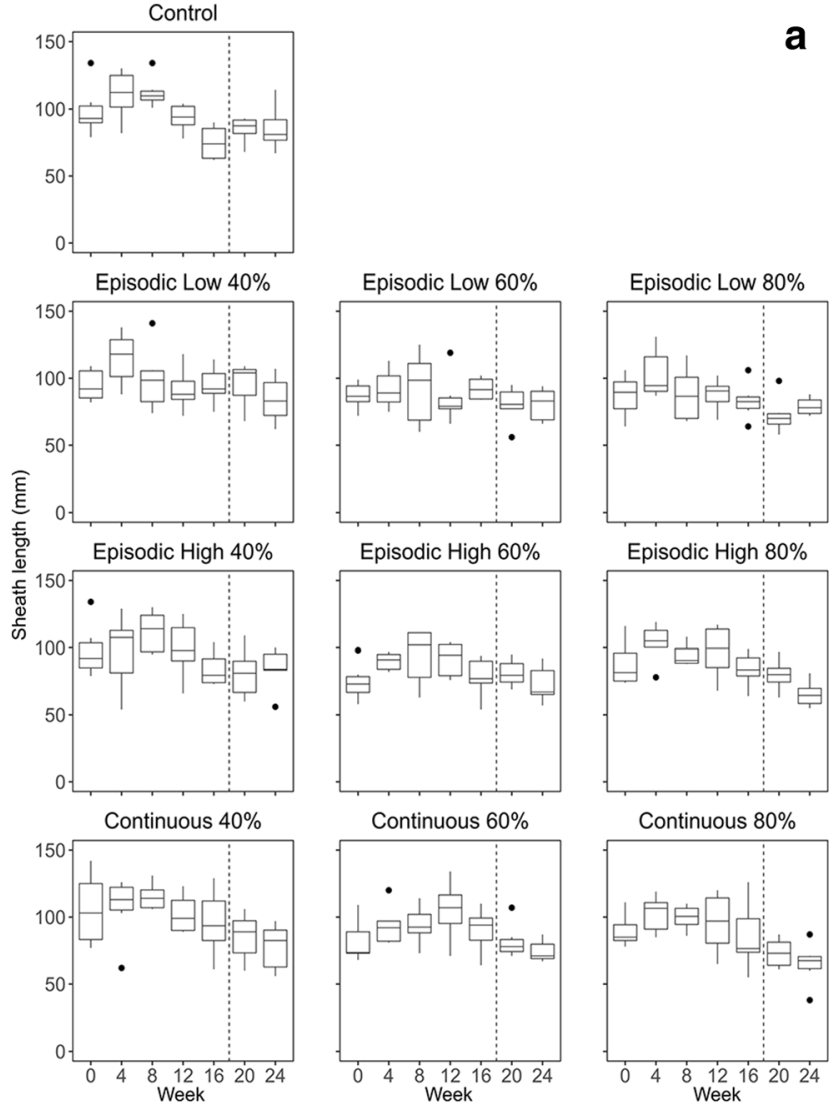

Episodic High 80\%

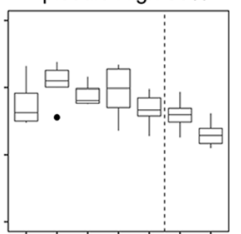

Continuous $80 \%$

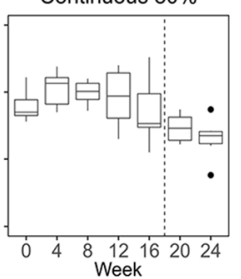

Fig. 5 a Sheath length during the light disturbance and recovery periods. Week 0 indicates when the light disturbance began, and the vertical dotted line indicates when shades were removed and recovery began (at 16 weeks). Boxplot as defined in Fig. 1. b Smoother functions for sheath length over time as estimated by
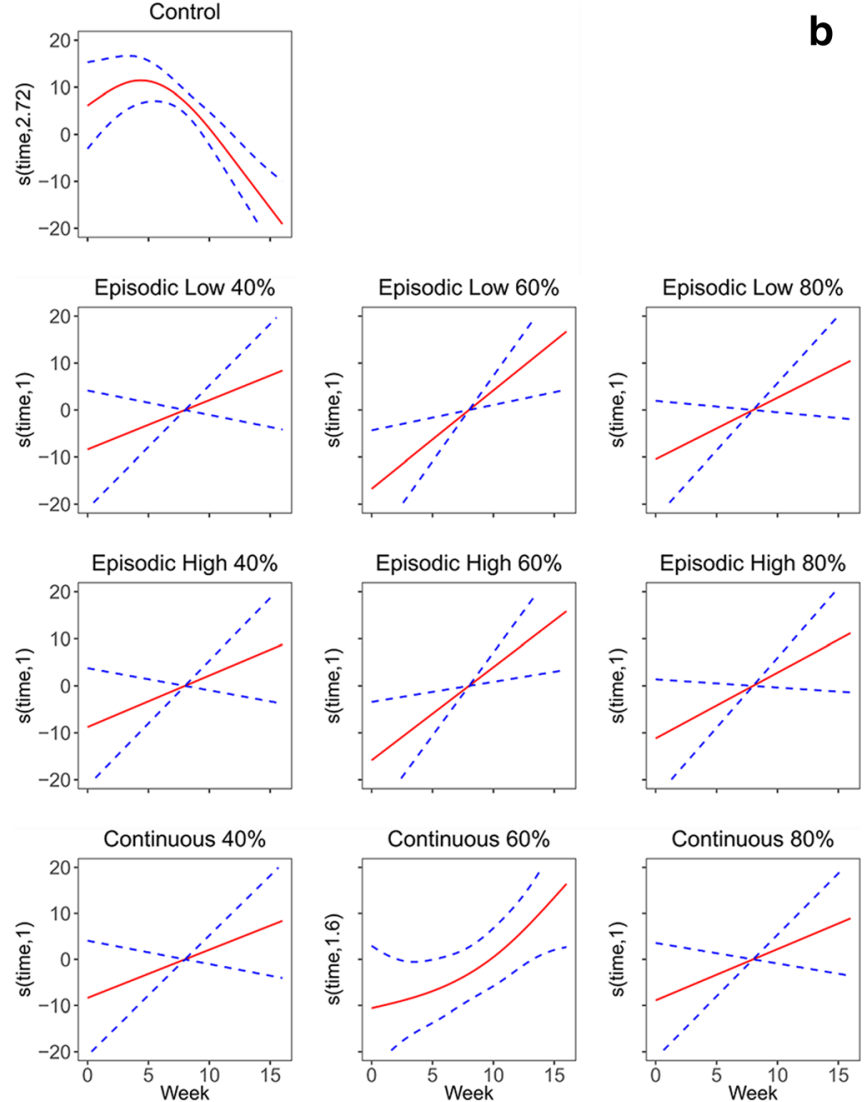

the GAMM regression for the light disturbance period. The red solid line indicates the estimated function, and the blue dotted lines indicate confidence intervals based on 2 standard errors. Numbers in the parentheses on the $y$-axes are the effective degrees of freedom for that treatment level 

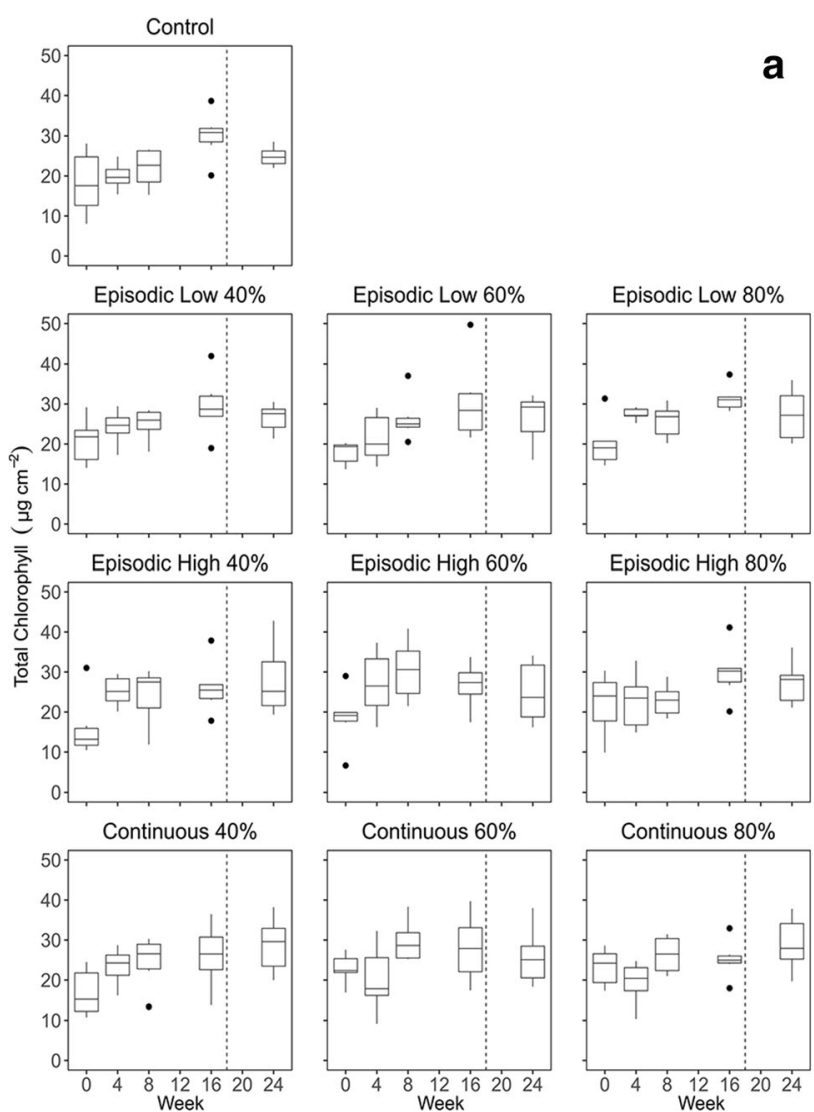

Continuous $60 \%$
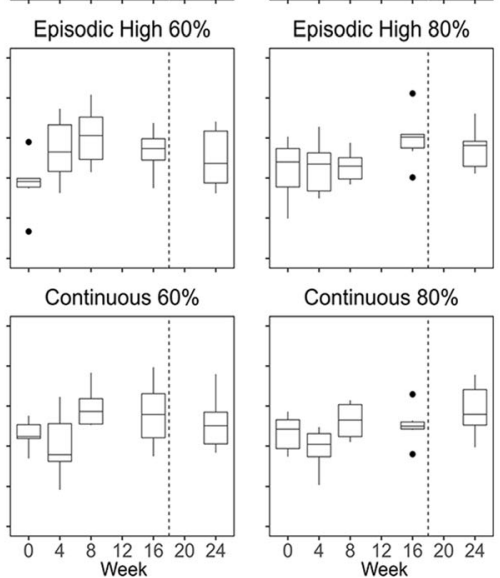

Fig. 6 a Total chlorophyll concentration during the light disturbance and recovery periods. Week 0 indicates when the light disturbance began, and the vertical dotted line indicates when shades were removed and recovery began (at 16 weeks). Boxplot as defined in Fig. 1. b Smoother functions for chlorophyll concentration over time as estimated by the GAMM

of episodic low disturbance at $80 \%$ shade (smoother term: $d f=1, F=3.05, p=0.082$ ) and episodic high disturbance at $60 \%$ shade (smoother term: $d f=2.11, F=3.91, p=0.021$ ).

Patterns in water-soluble carbohydrate (WSC) concentration of rhizomes over time were regulated by both the type of light disturbance and the degree of shading (GAMM regression: $R^{2}=0.40$; Electronic supplement $\mathrm{S} 1$ ). WSC rhizome concentration in control tanks initially increased from $\sim 200$ to $360 \mathrm{mg} \mathrm{g} \mathrm{DW}^{-1}$, and these levels were maintained throughout the light disturbance period (Fig. 7a). Similar trends were also observed in all disturbance regimes at 40 and $60 \%$ shade, where the smoother functions did not differ significantly from the controls. However, concentrations in continuous disturbance at $60 \%$ shade were lower overall during the light disturbance period compared with the controls. Declines in WSC rhizome concentrations relative to controls were evident during the early stages of light stress in all light disturbance regimes with $80 \%$ shade (smoother terms: $d f=2.33$ to $2.54, F=$ 2.24 to $5.09, p=0.005$ to 0.050 ; Fig. $7 \mathrm{~b}$ ). Here, the timing of the decline depended on the type of light disturbance, with concentrations decreasing later (week 8) in episodic low

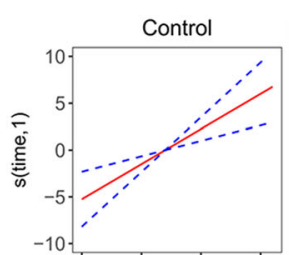

b
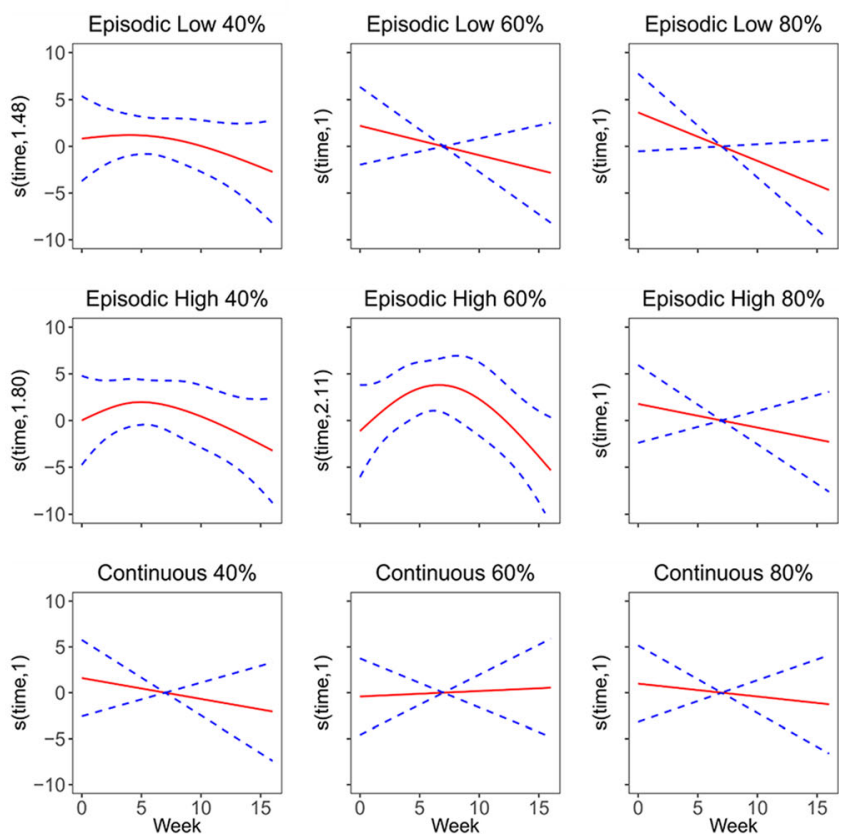

regression for the light disturbance period. The red solid line indicates the estimated function, and the blue dotted lines indicate confidence intervals based on 2 standard errors. Numbers in the parentheses on the $y$-axes are the effective degrees of freedom for that treatment level

disturbance compared with episodic high and continuous disturbance (week 4). Carbohydrate concentrations began to rebuild to background levels during the light stress period, beginning around week 12, although rebuilding was weakest in the continuous disturbance (Fig. 7a, b). During the recovery period, all WSC rhizome concentrations affected by light disturbance (i.e., continuous $60 \%$ shade, all light disturbance at $80 \%$ shade) increased and reached background levels by the end of the recovery period (Fig. 7a).

\section{Discussion}

We found that the relative importance of chronic versus episodic light disturbance on $Z$. marina survival was strongly modulated by the degree of shading. When shading was moderate and high (60 and $80 \%$ ), both chronic and episodic high light disturbance (i.e., long light stress relative to optimal light periods) had strong negative impacts on $Z$. marina density and biomass. Responses of $Z$. marina to these light delivery patterns were similar under moderate shade but differed under 

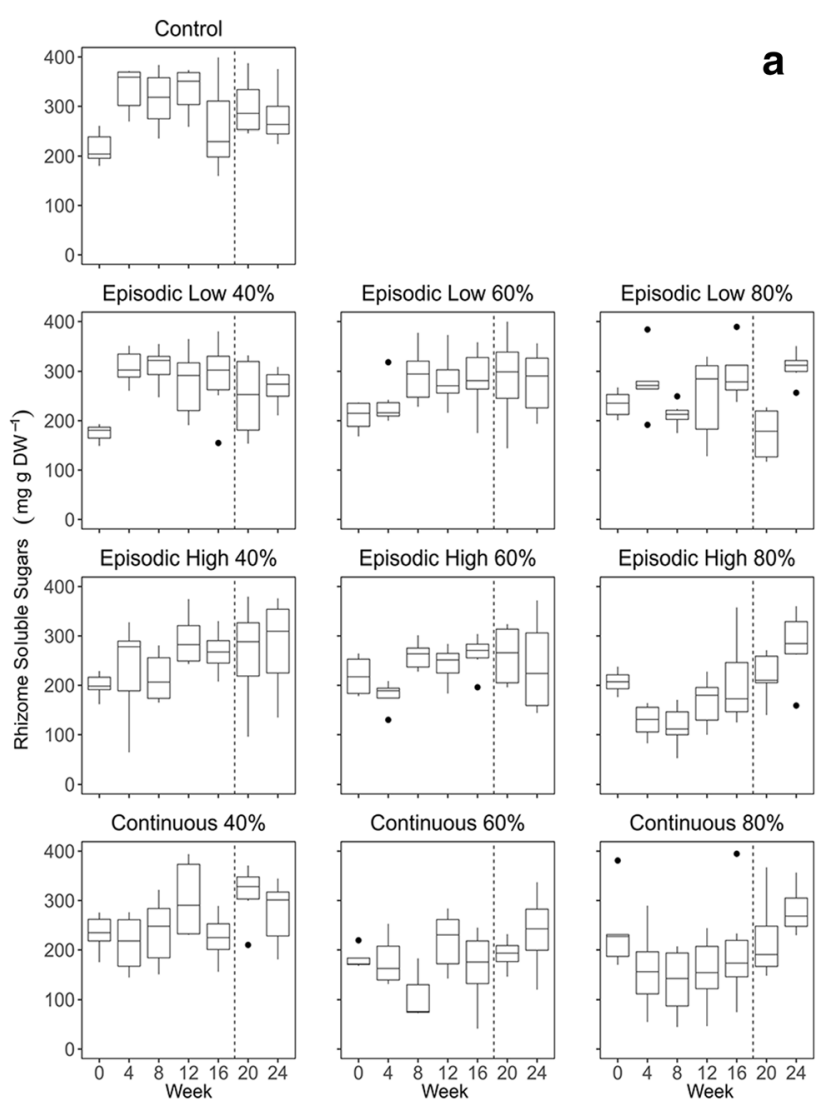

Fig. 7 a Water-soluble carbohydrate (WSC) concentration in the rhizomes during the light disturbance and recovery periods. Week 0 indicates when the light disturbance began, and the vertical dotted line indicates when shades were removed and recovery began (at 16 weeks). Boxplot as defined in Fig. 1. b Smoother functions for WSC

high shade, with continuous shading having stronger effects. When shading was low (40\%), only minimal impacts on Z. marina were evident across all light disturbance regimes, although chronic disturbance had larger impacts than either types of episodic light disturbance. Plant responses to episodic low disturbance (i.e., similar durations of light stress and optimal light) were not influenced by degree of shading, with declines in shoot density being similar across all shade levels and of less magnitude than in other light disturbance types.

Our study is, to our knowledge, one of the first to examine the relative importance of chronic and episodic light disturbance for Z. marina and how it is modulated by degree of shading. In tropical seagrasses, Statton et al. (2017) found that plants had similar responses to chronic and episodic light disturbance (12:2 days light stress and optimal light) when light stress was high $\left(2 \mathrm{~mol} \mathrm{~m}^{-2}\right.$ day $\left.^{-1}\right)$, and that the severity of response lessened under more moderate light stress ( 5 and 7 days at 2 and $4 \mathrm{~mol} \mathrm{~m}^{-2}$ day $^{-1}$, respectively). We also observed that decreased shade level reduced the impacts of episodic high light disturbance; however, we found that chronic light stress had stronger impacts than episodic, when shade level was high. Although the light delivery patterns in Statton
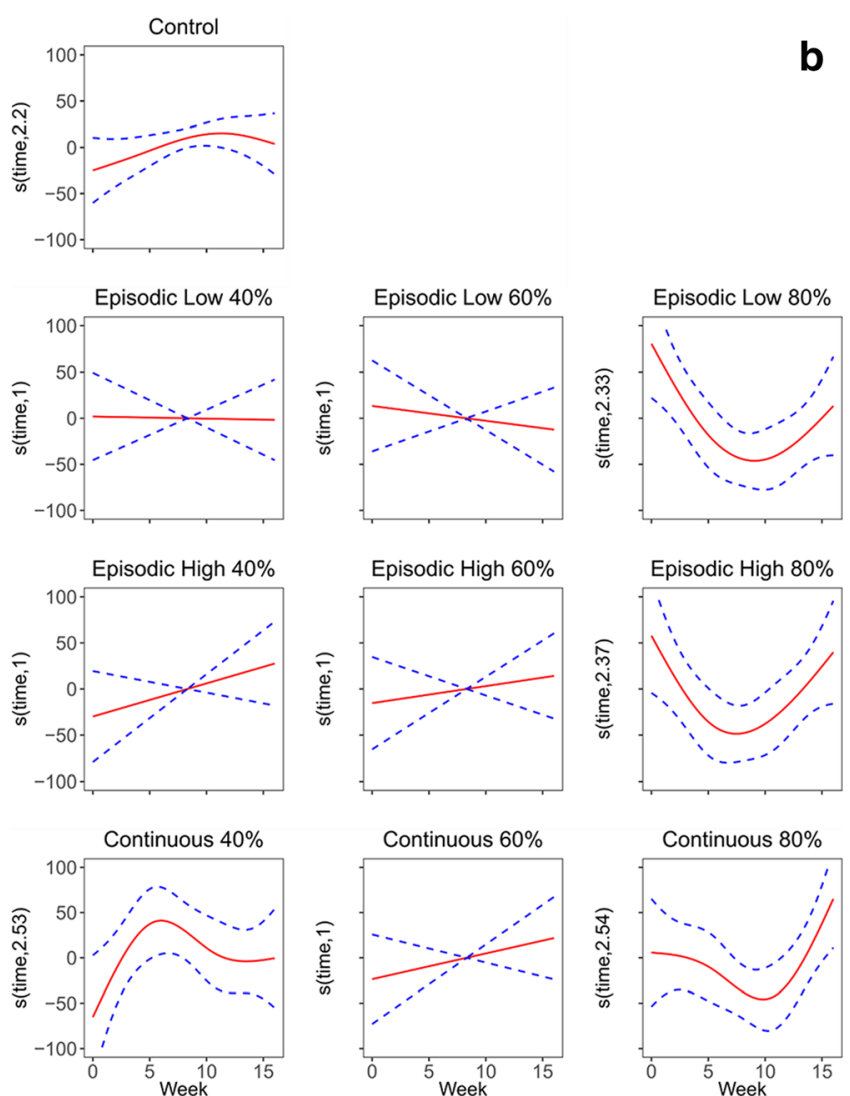

concentration over time as estimated by the GAMM regression for the light disturbance period. The red solid line indicates the estimated function, and the blue dotted lines indicate confidence intervals based on 2 standard errors. Numbers in the parentheses on the $y$-axes are the effective degrees of freedom for that treatment level

et al. (2017) matched our continuous and episodic high light disturbance treatments, and their light reductions were similar to absolute light values in our study, the longer overall light reduction period in our study (16 vs. 6 weeks) may have enhanced plant responses to chronic shading. However, it is difficult to make direct comparisons given large differences in species morphology, light requirements, and environmental conditions. We further extended the gradient of light disturbance in Statton et al. (2017) to include episodic low disturbance (4:3 days light stress and optimal light) and found that while negative impacts were evident, they were minimal relative to other light treatments. Biber et al. (2009) also examined both episodic low and high light disturbance (3:9, 3:3, 9:9, and 9:3 days darkness to light) using extreme shading (100\% darkness) in Z. marina and found similar results in that plant mortality was highest when periods of light stress were longer than optimal light periods. Our study further extends theirs to show that this response is modulated by shade level, with low shade having weaker effects than higher shade levels. In contrast with our results, Biber et al. (2009) found only minimal decreases in Z. marina density $(\leq 10 \%)$ when the duration of light stress equaled recovery, whereas we 
observed 16-24\% shoot mortality, depending on the shade level. This discrepancy is likely explained by differences in study duration; their study was shorter (1.5 months) and so included 3 or 7 cycles of equal light stress and optimal light periods, while our study was longer (4 months) and included 16 cycles. This indicates that even short light stress events punctuated by optimal light periods of near-equal duration can negatively impact seagrasses if they are repeated over the long term.

Chronic light disturbance in $Z$. marina ecosystems has been more widely examined, with studies showing similar results to ours in that chronic shading is detrimental to Z. marina survival and performance, especially with prolonged moderate to extreme shading (e.g., Fitzpatrick and Kirkman 1995; Hauxwell et al. 2003; Lavery et al. 2009; Kim et al. 2015; Wong et al. 2020). Our study further shows that episodic light disturbance consisting of long light stress and short optimal light periods can have similar negative effects as chronic shading, especially under moderate shade. Both chronic and episodic light disturbance remain relevant for Z. marina; chronic light stress from eutrophication, overwater structures, or long-term persistent turbidity have all been linked to increased Z. marina mortality and changes in distribution (Moore et al. 1997; Burdick and Short 1999; Hauxwell et al. 2003; Moore et al. 2012; Eriander et al. 2017), while episodic light disturbance from human activities or pulsed climatic events also have negative effects (this study; Biber et al. 2009; Statton et al. 2017).

The various responses of $Z$. marina to chronic and episodic light disturbance observed in our study reflect how these plants adjust their density, morphology and physiology to adapt to different light-stress scenarios. The high shoot mortality observed in some light disturbance regimes in our study reflects a common strategy employed by seagrasses to thin the canopy and reduce self-shading, effectively allowing more light availability for the remaining shoots (Dalla Via et al. 1998; Collier et al. 2009; Enríquez and Pantoja-Reyes 2005). Removal of biomass also allows light-stressed plants to reduce carbon demands for respiration and maintain overall carbon balance (Lee et al. 2007). Given the high light reductions in episodic high and continuous disturbance with 60 and $80 \%$ shade, it is not surprising that plants in these conditions had to drastically reduce their density to maintain carbon balance. Here, the optimal light portions of the pulsed light disturbance did not allow plants to compensate for impacts incurred during shading. Structural acclimation can be further achieved by increasing photosynthetic tissues relative to roots and rhizomes (Olesen and Sand-Jensen 1994); however, we did not observe disproportionate decreases in below- and aboveground biomass across light disturbance regimes. In fact, lateral shoots were evident in all light disturbance regimes at the end of the experiment, although we could not determine if growth occurred during the light reduction period, the recovery phase, or some combination of the two. In any case, we observed an overall reduction in growth in highly light stressed plants, which has been observed in other studies (Ochieng et al. 2010) and is thought to maintain low shoot density in turbid and deep waters (Moore et al. 1997; Krause-Jensen et al. 2000).

While our study shows that shading modulates how chronic and episodic light disturbance influence the density and biomass of $Z$. marina beds, the morphological response was primarily influenced by shading alone. Sheath length in almost all light disturbance regimes with 60 and $80 \%$ shade increased relative to controls over most of the light disturbance period, whereas sheath length of plants in $40 \%$ shade did not differ from controls. Sheath length is a reliable proxy for leaf growth in Z. marina (Gaeckle et al. 2006), and so these results indicate that plants in moderate and high shade were growing faster and longer leaves to produce more photosynthetic tissue, a common response of seagrasses in the early stages of light limitation (Bulthuis 1983; Abal et al. 1994; Longstaff and Dennison 1999; Lee et al. 2007). Plants appeared to favor increasing photosynthetic tissues to enhance light capture rather than increasing chlorophyll content, which remained lower than background levels throughout the experiment. The decrease in sheath length after prolonged shading (12 to 16 weeks) indicates a shift towards reducing respiratory demand by reducing growth (Collier et al. 2009; Lavery et al. 2009), rather than increasing leaf length to enhance photosynthetic capacity as observed earlier in the experiment.

The impacts of light reduction on concentrations of watersoluble rhizome carbohydrates (WSC) in Z. marina depended on both the type of light disturbance and shade level. Lower carbohydrate reserves in plants exposed to chronic and episodic light disturbance with $80 \%$ shade suggests that highly light-stressed plants either utilized stored nutrients or produced fewer to achieve carbon balance (Burke et al. 1996; Alcoverro et al. 1999). Carbohydrate concentrations in $80 \%$ shade were reduced earlier in continuous and episodic high light disturbance compared with episodic low disturbance, reflecting the higher metabolic requirements necessary for carbon balance in these conditions. Continuously shaded plants in $60 \%$ shade also either used more or produced fewer carbohydrates than episodically shaded plants at this shade level. The dependence of shaded seagrasses on carbohydrate reserves to maintain metabolic processes and ensure carbon balance has also been observed elsewhere (Burke et al. 1996; Collier et al. 2009; Lavery et al. 2009; Silva et al. 2013), particularly when light reduction is long and extreme. Changes to carbohydrate use and production during periods of light stress may be a last resort, as our study and others (Collier et al. 2009) showed that once carbon demand was reduced through shoot loss, carbohydrate concentrations began to rebuild. Interestingly, plants subjected to episodic light disturbance with 40 and $60 \%$ shade-maintained background 
carbohydrate concentrations, suggesting that plants in these conditions can rely on biomass and morphological changes alone for carbon balance. Plants in our experiment relied solely on their own carbohydrate reserves, as we used single shoots unattached to their neighbors. However, seagrasses often translocate nutrients from neighboring plants to support growth and survival (Marbà et al. 2002), with resource sharing being particularly useful when stressors are heterogeneous and some plants remain unaffected. Although resource translocation was not possible in our experiment, this likely had minimal effects on our results, given that the light disturbance was intended to be homogeneous and affect all plants equally.

In our study, experimental light disturbance was followed by an extended period of recovery where shades were removed and plants provided full undisrupted ambient light (same level as controls) for 8 weeks. Physiological measures (i.e., chlorophyll and WSC concentrations) impacted by light disturbance responded almost immediately to increased light availability and recovered quickly to background levels. However, the rapid recovery in physiology was not reflected by shoot density, biomass, or morphology. Shoot density and sheath length were not restored to background levels during the 2-month recovery period, and in many cases, continued to decline from values observed during light disturbance. Biomass was also not restored to background levels, with above- and belowground tissues still showing successive decreases across light disturbance regimes at the end of the recovery period. The disconnect between the rapid physiological response and recovery of shoot density, biomass, and morphology has also been observed in other studies (Collier et al. 2009; McMahon et al. 2011; Wong et al. 2020). While mechanisms underlying the reduction in growth of previously shaded plants in restored ambient light are unclear (Collier et al. 2009; McMahon et al. 2011; Wong et al. 2020), it is not particularly surprising that shoot density and biomass did not recover to pre-light disturbance levels, even after 2 months of restored ambient light. Recovery of shoot density in beds with low reproductive capacity depends on rhizome elongation and lateral shoot growth, which are relatively slow processes (Boese et al. 2009; Duarte 1991). Even small bare patches $\left(3\right.$ to $\left.4 \mathrm{~m}^{2}\right)$ in $Z$. marina beds can take 2 to 4 years to recolonize from lateral growth of adjacent shoots (Boese et al. 2009; Wong et al. 2020). Although we did not observe full recovery of plant density, lateral shoots were evident in all light disturbance regimes at the end of the recovery period, suggesting that plants were growing and recovery was underway.

Our study shows that not only does chronic shading of seagrass plants have detrimental effects on survival and performance (as is well established, e.g., Burdick and Short 1999; Hauxwell et al. 2003; Lavery et al. 2009; Kim et al. 2015; Wong et al. 2020), but episodic light disturbance can also have negative impacts. Further work is necessary to elucidate the resilience of $Z$. marina to various light disturbance scenarios across the full suite of environmental conditions it inhabits (Krumhansl et al. 2020). Our study represents Z. marina beds that are typically found in more exposed cool waters, with sandy sediments. Stronger responses may be evident for $Z$. marina beds in more protected warmer waters with muddy sediments high in organic content, as higher temperatures increase plant light requirements (Lee et al. 2007) and finer sediments can be high in sulfides, which reduce plant growth (Mascaro et al. 2009). Our light disturbance treatments also represent homogenous light stress across entire beds, which may have stronger impacts than more heterogeneous patterns in light reduction. Regardless, our study has important implications for the management of anthropogenic activities in the nearshore that reduce the underwater light climate for Z. marina. Activities that create pulsed light disturbance, such as dredging, should be adjusted to include optimal light periods that are equal or longer in duration to periods of light stress, especially when light reduction is moderate or high. Pattern of light delivery may not be as critical when light reduction is low, as our results suggest that $Z$. marina can tolerate high episodic light disturbance (i.e., long light stress: short optimal periods light) or even chronic light limitation, when shading is minimal. Furthermore, light disturbance should be timed to occur when Z. marina is most seasonally resilient to reduced light conditions, which in cooler waters is usually the spring/summer when natural photoperiod is long (Wong et al. 2020). Attention to these aspects can reduce plant mortality and build resilience to light disturbance events, supporting the long-term persistence of seagrass ecosystems.

Acknowledgments We are grateful to A. Campbell, J. Hogenbom, D. Krug, B. Roethlisberger, M. Scarrow, and C. Siong for assistance during the laboratory experiment. The manuscript was improved by comments from anonymous reviewers.

Funding Information Funding was provided by Fisheries and Oceans Canada.

Open Access This article is licensed under a Creative Commons Attribution 4.0 International License, which permits use, sharing, adaptation, distribution and reproduction in any medium or format, as long as you give appropriate credit to the original author(s) and the source, provide a link to the Creative Commons licence, and indicate if changes were made. The images or other third party material in this article are included in the article's Creative Commons licence, unless indicated otherwise in a credit line to the material. If material is not included in the article's Creative Commons licence and your intended use is not permitted by statutory regulation or exceeds the permitted use, you will need to obtain permission directly from the copyright holder. To view a copy of this licence, visit http://creativecommons.org/licenses/by/4.0/. 


\section{References}

Abal, E.G., N. Loneragan, P. Bowen, C.J. Perry, J.W. Udy, and W.C. Dennison. 1994. Physiological and morphological responses of the seagrass Zostera capricorni Aschers, to light intensity. Journal of Experimental Marine Biology and Ecology 178 (1): 113-129.

Alcoverro, T., R.C. Zimmerman, D.G. Kohrs, and R.S. Alberte. 1999. Resource allocation and sucrose mobilization in light-limited eelgrass Zostera marina. Marine Ecology Progress Series 187: 121131.

Biber, P.D., W.J. Kenworthy, and H.W. Paerl. 2009. Experimental analysis of the response and recovery of Zostera marina (L.) and Halodule wrightii (Ascher.) to repeated light-limitation stress. Journal of Experimental Marine Biology and Ecology 369 (2): $110-117$.

Boese, B.L., J.E. Kaldy, P.J. Clinton, P.M. Eldridge, and C.L. Folger. 2009. Recolonization of intertidal Zostera marina L.(eelgrass) following experimental shoot removal. Journal of Experimental Marine Biology and Ecology 374 (1): 69-77.

Bulthuis, D.A. 1983. Effects of in situ light reduction on density and growth of the seagrass Heterozostera tasmanica (martens ex Aschers.) den Hartog in Western port, Victoria, Australia. Journal of Experimental Marine Biology and Ecology 67 (1): 91-103.

Burdick, D.M., and F.T. Short. 1999. The effects of boat docks on eelgrass beds in coastal waters of Massachusetts. Environmental Management 23 (2): 231-240.

Burke, M.K., W.C. Dennison, and K.A. Moore. 1996. Non-structural carbohydrate reserves of eelgrass Zostera marina. Marine Ecology Progress Series 137: 195-201.

Collier, C.J., P.S. Lavery, P.J. Ralph, and R.J. Masini. 2009. Shadeinduced response and recovery of the seagrass Posidonia sinuosa. Journal of Experimental Marine Biology and Ecology: 370.

Dalla Via, J., C. Sturmbauer, G. Schönweger, E. Sötz, S. Mathekowitsch, M. Stifter, and R. Rieger. 1998. Light gradients and meadow structure in Posidonia oceanica: Ecomorphological and functional correlates. Marine Ecology Progress Series 163: 267-278.

Duarte, C.M. 1991. Seagrass depth limits. Aquatic Botany 40 (4): 363 377.

Enríquez, S., and N.I. Pantoja-Reyes. 2005. Form-function analysis of the effect of canopy morphology on leaf self-shading in the seagrass Thalassia testudinum. Oecologia 145 (2): 235-243.

Eriander, L., K. Laas, P. Bergström, L. Gipperth, and P.O. Moksnes. 2017. The effects of small-scale coastal development on the eelgrass (Zostera marina L.) distribution along the Swedish west coast ecological impact and legal challenges. Ocean \& coastal management 148: 182-194.

Fitzpatrick, J., and H. Kirkman. 1995. Effects of prolonged shading stress on growth and survival of seagrass Posidonia australis in Jervis Bay, New South Wales, Australia. Marine Ecology Progress Series 127: 279-289.

Gaeckle, J.L., F.T. Short, S.E. Ibarra-Obando, and A.E. Meling-López. 2006. Sheath length as a monitoring tool for calculating leaf growth in eelgrass (Zostera marina L.). Aquatic Botany 84 (3): 226-232.

Giesen, W.B.J.T., M.M. Van Katwijk, and C. Den Hartog. 1990. Eelgrass condition and turbidity in the Dutch Wadden Sea. Aquatic Botany 37 (1): 71-85.

Hauxwell, J., J. Cebrián, and I. Valiela. 2003. Eelgrass Zostera marina loss in temperate estuaries: Relationship to land-derived nitrogen loads and effect of light limitation imposed by algae. Marine Ecology Progress Series 247: 59-73.

Hitchcock, J.K., S.C. Courtenay, M.R.S. Coffin, C.C. Pater, and M.R. van den Heuvel. 2017. Eelgrass bed structure, leaf nutrient, and leaf isotope responses to natural and anthropogenic gradients in estuaries of the southern Gulf of St. Lawrence, Canada. Estuaries and Coasts 40 (6): 1653-1665.
Kim, Y.K., S.H. Kim, and K.-S. Lee. 2015. Seasonal growth responses of the seagrass Zostera marina under severely diminished light conditions. Estuaries and Coasts 38 (2): 558-568.

Krause-Jensen, D., A.L. Middelboe, K. Sand-Jensen, and P.B. Christensen. 2000. Eelgrass Zostera marina, growth along depth gradients: Upper boundaries of the variation as a powerful predictive tool. Oikos 91 (2): 233-244.

Krumhansl, K., M. Dowd, and M.C. Wong. 2020. A characterization of the physical environment at seagrass sites along the Atlantic coast of Nova Scotia. Canadian Technical Report of Fisheries and Aquatic Sciences 3361: v +213 pp.

Lavery, P.S., K. McMahon, M. Mulligan, and A. Tennyson. 2009. Interactive effects of timing, intensity and duration of experimental shading on Amphibolis griffithii. Marine Ecology Progress Series 394: 21-33.

Lee, K.S., S.R. Park, and Y.K. Kim. 2007. Effects of irradiance, temperature, and nutrients on growth dynamics of seagrasses: A review. Journal of Experimental Marine Biology and Ecology 350 (1-2): 144-175.

Lefcheck, J.S., D.J. Wilcox, R.R. Murphy, S.R. Marion, and R.J. Orth. 2017. Multiple stressors threaten the imperiled coastal foundation species eelgrass (Zostera marina) in Chesapeake Bay, USA. Global Change Biology 23 (9): 3474-3483.

Longstaff, B.J., and W.C. Dennison. 1999. Seagrass survival during pulsed turbidity events: The effects of light deprivation on the seagrasses Halodule pinifolia and Halophila ovalis. Aquatic Botany 65 (1-4): 105-121.

Marbà, N., M.A. Hemminga, M.A. Mateo, C.M. Duarte, Y.E.M. Mass, J. Terrados, and E. Gacia. 2002. Carbon and nitrogen translocation between seagrass ramets. Marine Ecology Progress Series 226: 287-300.

Mascaro, O., T. Valdemarsen, M. Holmer, M. Perez, and J. Romero. 2009. Experimental manipulation of sediment organic content and water column aeration reduces Zostera marina (eelgrass) growth and survival. Journal of Experimental Marine Biology and Ecology 373 (1): 26-34.

Masuko, T., A. Minami, N. Iwasaki, T. Majima, S.I. Nishimura, and Y.C. Lee. 2005. Carbohydrate analysis by a phenol-sulfuric acid method in microplate format. Analytical Biochemistry 339 (1): 69-72.

McMahon, K., P.S. Lavery, and M. Mulligan. 2011. Recovery from the impact of light reduction on the seagrass Amphibolis griffithii, insights for dredging management. Marine Pollution Bulletin 62 (2): 270-283.

McMahon, K., C. Collier, and P.S. Lavery. 2013. Identifying robust bioindicators of light stress in seagrasses: A meta-analysis. Ecological Indicators 30: 7-15.

Moore, K.A., R.L. Wetzel, and R.J. Orth. 1997. Seasonal pulses of turbidity and their relations to eelgrass (Zostera marina L.) survival in an estuary. Journal of Experimental Marine Biology and Ecology 215 (1): 115-134.

Moore, K.A., E.C. Shields, D.B. Parrish, and R.J. Orth. 2012. Eelgrass survival in two contrasting systems: Role of turbidity and summer water temperatures. Marine Ecology Progress Series 448: 247-258.

Murphy, G.E.P., M.C. Wong, and H.K. Lotze. 2019. A human impact metric for coastal ecosystems with application to seagrass beds in Atlantic Canada. Facets 4 (1): 210-237.

Ochieng, C.A., F.T. Short, and D.I. Walker. 2010. Photosynthetic and morphological responses of eelgrass (Zostera marina L.) to a gradient of light conditions. Journal of Experimental Marine Biology and Ecology 382 (2): 117-124.

Olesen, B., and K. Sand-Jensen. 1994. Biomass-density patterns in the temperature seagrass Zostera marina. Marine Ecology Progress Series 109: 283-291.

Olsen, Y.S., M. Sánchez-Camacho, N. Marbà, and C.M. Duarte. 2012. Mediterranean seagrass growth and demography responses to experimental warming. Estuaries and Coasts 35 (5): 1205-1213. 
Orth, R.J., T.J.B. Carruthers, W.C. Dennison, C.M. Duarte, J.W. Fourqurean, K.L. Heck, A.R. Hughes, et al. 2006. A global crisis for seagrass ecosystems. Bioscience 56 (12): 987-996.

Ralph, P.J., M.J. Durako, S. Enríquez, C.J. Collier, and M.A. Doblin. 2007. Impact of light limitation on seagrasses. Journal of Experimental Marine Biology and Ecology 350 (1-2): 176-193.

Ritchie, R.J. 2006. Consistent sets of spectrophotometric chlorophyll equations for acetone, methanol and ethanol solvents. Photosynthesis Research 89 (1): 27-41.

Shoaf, W.T., and B.W. Lium. 1976. Improved extraction of chlorophyll a and $\mathrm{b}$ from algae using dimethyl sulfoxide. Limnology and Oceanography 21 (6): 926-928.

Short, F.T., and S. Wyllie-Echeverria. 1996. Natural and human-induced disturbance of seagrasses. Environmental Conservation 23 (1): 1727.

Silva, J., I. Barrote, M.M. Costa, S. Albano, and R. Santos. 2013. Physiological responses of Zostera marina and Cymodocea nodosa to light-limitation stress. PLoS One 8 (11): e81058. https://doi.org/ 10.1371/journal.pone.0081058.

Skinner, M.A., S.C. Courtenay, and C.W. McKindsey. 2013. Reductions in distribution, photosynthesis, and productivity of eelgrass Zostera marina associated with oyster Crassostrea virginica aquaculture. Marine Ecology Progress Series 486: 105-119.

Statton, J., K.M. McMahon, R. McCallum, G.A. Kendrick, and P.S. Lavery. 2017. Response and recovery of a mixed tropical seagrass assemblage to variation in the frequency and magnitude of light deprivation. Report of theme 5 - project 5.5 .3 prepared for the Dredging Science Node, 55. Perth: Western Australian Marine Science Institution.
Touchette, B.W., and J.M. Burkholder. 2000. Overview of the physiological ecology of carbon metabolism in sea grasses. Journal of Experimental Marine Biology and Ecology 250 (1-2): 169-205.

Unsworth, R.K.F., C.J. Collier, M. Waycott, L.J. Mckenzie, and L.C. Cullen-Unsworth. 2015. A framework for the resilience of seagrass ecosystems. Marine Pollution Bulletin. 100 (1): 34-46.

Valiela, I., J. McClelland, J. Hauxwell, P.J. Behr, D. Hersh, K. Foreman, and K. 1997. Macroalgal blooms in shallow estuaries: Controls and ecophysiological and ecosystem consequences. Limnology and Oceanography 42: 1105-1118.

Waycott, M., C.M. Duarte, T.J.B. Carruthers, R.J. Orth, W.C. Dennison, S. Olyarnik, A. Calladine, J.W. Fourqurean, K.L. Heck, A.R. Hughes, G.A. Kendrick, W.J. Kenworthy, F.T. Short, and S.L. Williams. 2009. Accelerating loss of seagrasses across the globe threatens coastal ecosystems. Proceedings of the National Academy of Sciences of the United States of America 106: 1237712381.

Wong, M.C. 2018. Secondary production of macrobenthic communities in seagrass (Zostera marina, eelgrass) beds and bare soft sediments across differing environmental conditions in Atlantic Canada. Estuaries and Coasts 41 (2): 536-548.

Wong, M.C., G. Griffiths, and B. Vercaemer. 2020. Seasonal response and recovery of eelgrass (Zostera marina) to short-term reductions in light availability. Estuaries and Coasts 43 (1): 120-134.

Wood, S.N. 2017. Generalized additive models: An introduction with R. 2nd ed. Boca Raton: CRC Press.

Yaakub, S.M., E. Chen, T.J. Bouma, P.L.A. Erftemeijer, and P.A. Todd. 2014. Chronic light reduction reduces overall resilience to additional shading stress in the seagrass Halophila ovalis. Marine Pollution Bulletin 83 (2): 467-474. 